\title{
THE IMPROVEMENT OF THE INTERESEST IN LEARNING SOCIAL SCIENCES USING JOYFUL LEARNING STRATEGY SUPPORTED BY FUN SOCIAL PUZZLE MEDIA
}

\author{
Sifa Adriani Prihatina, Sukarno, Endang Sri Markamah
}

Universitas Sebelas Maret

sukarno57@staff.uns.ac.id

Article History

accepted 09/07/2018

approved 01/08/2018

published 17/09/2018

\section{Keywords}

Interest ini Learningsocial sciences, Joyful

Learningstrategy, Fun

Social Puzzle media

\begin{abstract}
The objectives of this research are to: 1) improve the interest in Learning social sciences through the use of Joyful Learning strategy with Fun Social Puzzle media on 4th grade students 2) describe the use and the result of Joyful Learning strategy with Fun Social Puzzle media in improving the interest in Learning social science on $4^{\text {th }}$ grade students. The sources of data come from researcher, teachers, and students. The data collection techniques used are: interview, observation, and interest questionnaires. The data validity test techniques used are triangulation sources and methods. Data analysis techniques used are comparative descriptive analysis and interactive analysis models. The results of this research indicate that the interest in Learning social sciences on 4th grade students using Joyful Learning strategy with Fun Social Puzzle media improves. The improvement is seen by the number of students in high interest category and very high category increase. On pre-action, students who have a high interest and very high interest on the social sciences subjects are only $32 \%$. In cycle I it increases to $63 \%$. In the end of the cycle II it increases to $93 \%$ or 28.
\end{abstract}

Social, Humanities, and Education Studies (SHEs): Conference Series https://jurnal.uns.ac.id/shes

p-ISSN 2620-9284 e-ISSN 2620-9292 


\section{PENDAHULUAN}

Minat mempunyai peran yang penting dalam proses pembelajaran. Peran tersebut membuat siswa menjadi lebih bersemangat dan atusias mengikuti kegiatan pembelajaran di kelas. Siswa lebih tergugah untuk bertanya dan menjawab pertanyaan dari guru sehingga mereka paham dalam mempelajari materi pelajaran. Karenanya minat itu mempengaruhi kualitas dalam pencapaian hasil belajar pada bidang studi tertentu (Syah, 2012). Salah satu bidang studinya ialah IImu Pengetahuan Sosial (IPS). Pada IPS materinya dititikberatkan pada pengalaman lingkungan siswa, kehidupan masyarakat sekitar. Sehingga untuk memunculkan minat belajar akan IPS tidak begitu sulit. Meskipun begitu, menumbuhkan minat menjadi tantangan tersendiri dan tuntunan guru ketika mengajarkan suatu pelajaran.

Hasil dari observasi sebelumtindakan menunjukkan banyak siswa yang kurang memperhatikan penjelasan guru saat mengajar tentang materi IPS. Siswa cenderung ribut dan menghambat proses pembelajaran. Perilaku-perilaku tersebut menandakan tidak adanya minat akan belajar materi IPS.Hal tersebut memberi dampak pada prestasi belajar yang rendah.

Berdasarkan hasil wawancara pada beberapa siswa dan guru kelas IV menunjukkan bahwa memang siswa kelas IV memerlukan bimbingan mengenai minat belajar mereka. Siswa kurang menaruh perhatian dalam materi IPS dan enggan untuk membaca buku yang terkait materi IPS. Keengganan tersebut mengakibatkan hasil belajar yang kurang memuaskan. Bahkan ada beberapa siswa yang tidak memenuhi Kriteria Ketuntasan Minimal (KKM).

Hasil angket minat belajar IPS yang telah disebar menunjukkan bahwa dari 30 siswa hanya 10 atau $32 \%$ siswa yang memiliki minat belajar tinggi dan sangat tinggi. Selebihnya 20 siswa atau $68 \%$ siswa memiliki minat belajar IPS sedang, rendah dan sangat rendah. Berdasarkan hasil terebut, menandakan bahwa minat belajar IPS siswa kelas IV masih tergolong rendah.

Berdasarkan penjabaran masalah di atas perlu diadakan upaya untuk peningkatan mengenai minat belajar IPS siswa. Usaha yang dilakukan salah satunya menggunakan strategi yang memang efektif untuk menumbuhkan minat. Strateginya ialah Joyful Learning. Joyful Learningialah suatu pengorganisasian pembelajaran dengan cara meningkatkan daya tarik pembelajaran melalui bahan ajar, media pembelajaran, dan pengalokasian waktu pengajaran (Darmansayah, 2014). Strategi Joyful Learningmemberikan kenyaman, rasa aman serta menyenangkan pada siswa untuk mengikuti pembelajaran. Pada strategi ini pula ditekankan pada proses belajar atau pengalaman siswa yang di dapatkan dalam kelas. Joyful Learningjuga memberanikan siswa untuk bertanya, menjawab, mengemukakan pendapat tanpa takut diintimidasi atau diremehkan teman lainnya (Permatasari, 2014).

Oleh sebab itu, strategi Joyful Learningdapat diterapkan pada materi IPS guna meningkatkan minat belajar siswa. Penggunaan strategi ini memungkinkan siswa nyaman, senang dan tertarik untuk belajar. Jika siswa sudah tertarik ia akan berminat belajar materi IPS hari ini, esok dan seterusnya.

Strategi Joyful Learningakan lebih maksimal jika dibarengi dengan media pembelajaran. Wei (2011) mengungkapkan bahwa instruktur (guru) dapat memanfaatkan materi pembelajaran secara fisik, yaitu menggunakan media untuk meningkatkan kesadaran siswa tentang isi pembelajaran. Salah satu media yang cocok dengan startegi tersebut ialah media puzzle. Puzzlemerupakanpermainan yang membutuhkan kesabaran dam ketekunan anak dalam merangkainya. Terdiri dari kepingan tipis yang terdiri dai 2-3 atau lebih potongan yang terbuat dari kayu atau lempeng karton. Denganterbiasabermainpuzzlelambatlaun mental siswa juga akan terbiasa untuk bersikap tenang, tekun dan sabar dalam menyelesaikan sesuatu. Kepuasan yang didapat saat siswa menyelesaikan puzzle pun merupakan salah satu 
pembangkit minat siswa untuk hal-hal yang baru (Widyanarti, 2014). Materi IPS kelas IV yang cenderung menyangkut lingkungan siswa sehari-hari pun mudah jika dituangkan dalam media puzzle.

\section{METODE}

Penelitian ini merupakan Penelitian Tindakan Kelas (PTK) yang dilakukan di SD N Mangkuyudan No.2 Surakarta pada bulan Januari-Agustus 2018. Subjek pada penelitian ini adalah siswa kelas IV yang berjumlah 30 siswa, terdiri dari 17 siswa lakilaki dan 13 siswa perempuan.

Teknik pengumpulan data yaitu melalui observasi, wawancara dan angket. Uji validitas data dilakukan dengan triangulasi sumber dan metode. Penelitian ini menggunakan teknik analisis data model interaktif Miles dan Huberman yang terdiri dari tiga tahap, yaitu reduksi data, penyajian data dan penarikan kesimpulan.

\section{HASIL DAN PEMBAHASAN}

Penelitianinidilakukanselama 2 siklus. Masing-masingsiklusterdiridari 2 kali pertemuandenganalokasiwaktu 3 × 35 menit. Tahapan dari setiap siklusmeliputi tahap perencanaan, pelaksanaan, pengamatan dan refleksi.

Hasil analisis data minat belajar IPS siswa kelas IV pada setiap tindakan mengalami peningkatan dibandingkan pada pra-tindakan. Adapun perbandingan peningkatan minat belajar IPS siswa antar siklus dapat dihat pada gambar 1 .

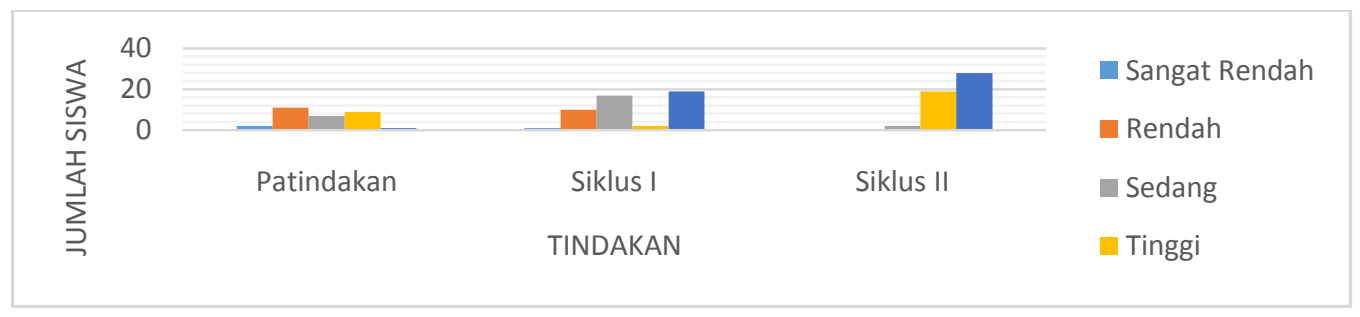

\section{Gambar 1.Diagram PerbandinganHasilMinatBelajar IPSPra- Tindakan, Siklus I danSiklus II}

Pada saat pra-tindakan siswa yang mempunyai minat tinggi dan sangat tinggi berjumlah 10 siswa. Pada siklus I naik menjadi 19 siswa dan pada akhir siklus II menjadi 24 siswa. Persentase rata-rata minat belajar IPS siswa kategori tinggi dan sangat tinggi pada pratindakan ialah $32 \%$ meningkat $31 \%$ pada siklus I menjadi $63 \%$ dan menjadi $93 \%$ pada siklus II.

Selain itu, aspek minat belajar IPS siswa juga mengalami kenaikan. Mulai dari aspek partisipasi, perhatian, interaksi, penugasan dan kedisiplinan. Dari skor-skor yang diperoleh, dirata-rata sebagai berikut. Pada pra-tindakan rata-rata skor per aspeknya ialah 80,7 menjadi 93,6 pada siklus I dan menjadi 101,2 pada siklus II. Kenaikan ratarata skor minatbelajar IPS per aspekpadatindakan dapat dilihat pada Gambar2.

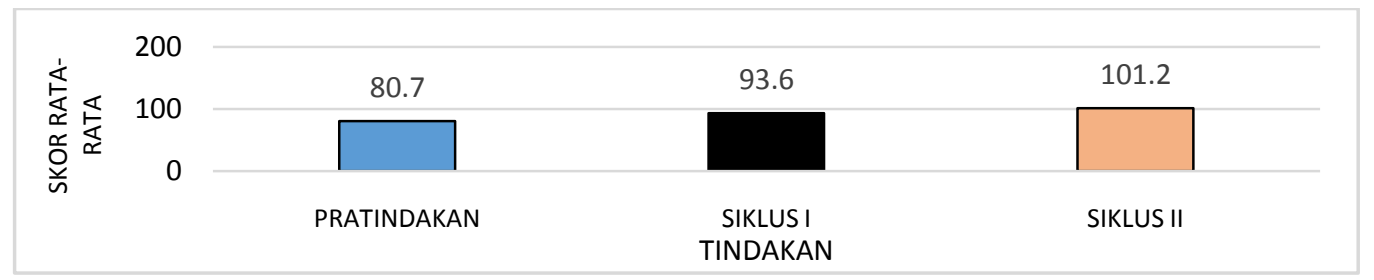

Gambar 2. DiagramPerbandinganSkor Rata-rata Minat Belajar IPS per Aspek pada Tindakan 
Peningkatan minat siswa tersebut tidak terlepas dari peran guru dalam pembelajaran menggunakan strategi Joyful Learningberbantuan mediaFun Social Puzzle. Peran guru tersebut terangkum dalam kinerja guru. Kinerja gurupun mengalami peningkatan, skor pada siklus I sebesar 30 (kategori cukup baik) dan pada siklus II 50,5 (kategori baik).

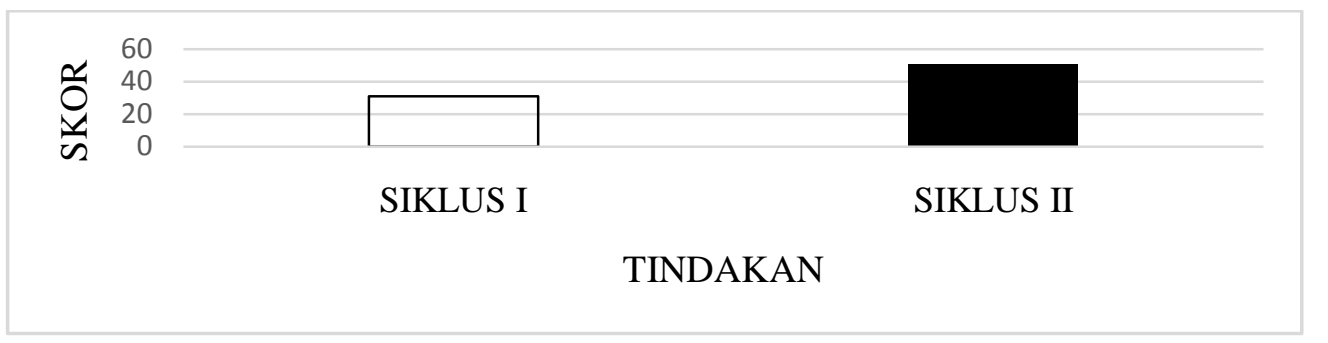

\section{Gambar 3. Diagram PerbandinganHasil Kinerja Guru pada Siklus I dan II}

Aktivitas siswa yang diamati pun menampakan kesesuaian dengan peningkatan minat terhadap pembelajaran. Hasil rata-rata skor aktivitas siswa mengalami kenaikan pada akhir siklus II. Pada siklus I hasil rata-rata aktivitas siswanya sebesar 8,6 dan dalam kategori baik. Pada akhir siklus II mengalami kenaikan skor sebanyak 3,4 menjadi 12, kategori sangat baik. Perbandinganpeningakatanhasil rata-rata aktivitassiswasiklus I dan II dapat dilihat pada gambar 4.

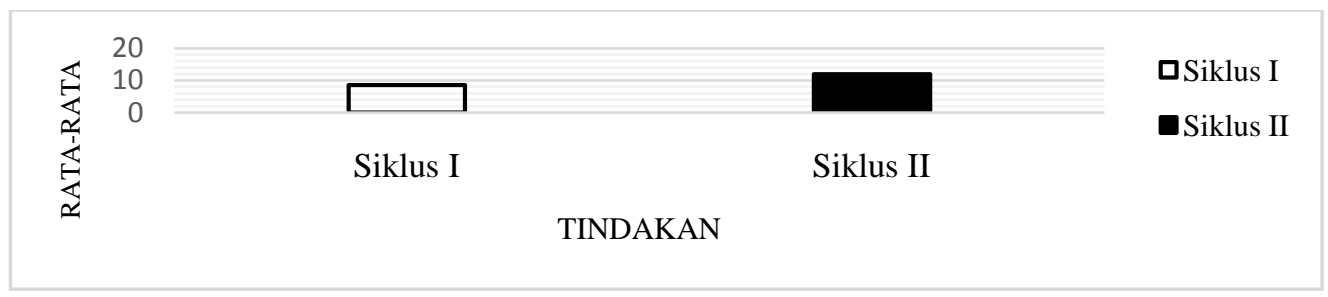

\section{Gambar 4. Diagram Perbandingan Hasil Rata-rata Aktivitas Siswa Siklus I dan II}

Peningkatan minat belajar IPS tersebut dikarenakan dalam proses pembelajaran (tindakan pada siklus I dan siklus II) menggunakan strategi Joyful Learning serta media puzzle. Penggunaan strategi dan media tersebut membuat perhatian siswa terfokus untuk belajar tanpa adanya tekanan yang dirasakan. Sehingga siswa berminat untuk mempelajari materi IPS. Pada keadaan yang nyaman ini siswa kelas IV SD N Mangkuyudan lebih berminat untuk belajar. Siswa berani mencoba, bertanya tanpa takut disalahkan dan diejek oleh teman lainnya. Selain itu siswa juga lebih antusias untuk melakukan berbagai kegiatan pembelajaran di kelas. Siswa bersemangat untuk menyusun puzzle. Siswa berlomba-lomba untuk cepat menyelesaikan dan menyususn informasi yang terdapat pada puzzlenya.

Guru (peneliti) telah melakukan kegiatan pembelajaran sesuai dengan langkah pada Rencana Pelaksanaan Pembelajaran (RPP). Langkah-langkah pada RPP juga disusun berdasarkan langkah pada strategi Joyful Learning. Kesesuaian pembelajaran dengan langkah-langkah mengakibatkan skor kinerja guru meningkat pada setiap pertemuan. Pada siklus I skor rata-rata kinerja guru sebanyak 30 termasuk dalam kategori cukup. Pada siklus II skor kinerja gurunya meningkat menjadi 50,5 termasuk dalam kategori baik. Artinya dari diklus I ke siklus II meningkat sebanyak 20,5 poin. Ada beberapa hal yang meningkat dalam pembelajaran menggunakan strategi Joyful Learningberbantuan media puzzle yaitu: 1) pada tahap persiapan. Guru sudah dapat 
menimbulkan minat awal belajar pada siswa. 2) pada tahap penyampaian. Guru sudah mampu menyampaikan materi pelajaran dengan baik dengan melibatkan siswa dalam pembelajaran. 3) tahap pelatihan. Penggunaan media puzzle oleh guru dilakukan pada saat mengerjakan Lembar Kerja Siswa (LKS) . 4) tahap penutup. Siswa diajak guru untuk membuat kesimpulan pembelejaran bersama, kemudian diakhiri dengan bernyanyi bersama.

Aktivitas siswa yang diamati pun menampakan kesesuaian dengan peningkatan minat terhadap pembelajaran. Pada siklus I hasil rata-rata aktivitas siswanya sebesar 8,6 dan dalam kategori baik. Pada akhir siklus II mengalami kenaikan skor sebanyak 3,4 menjadi 12, rata-rata skor tersebut temasuk dalam kategori sangat baik. Hal tersebut menandakan bahwa penggunaan strategi Joyful Learningberbantuan media puzzle berhasil. Terlihat pada akhir siklus II skor setiap aspek meningkat. Perhatian siswa dalam pembalajaran termasuk baik. Siswa juga sudah mau berpartisipasi dan berinteraksi dalam setiap kegitan berkelompok (diskusi) dengan baik. Kedisiplinan siswa pun baik, siswa mau mengumpulkan tugas kelompok tepat waktu dan siswa yang terlambat masuk kelaspun berkurang. Hal tersebutpun sesuai dengan penelitian yang dilakukan oleh Proity (2013), bahwa strategi Joyful Learning efektif untuk meningkatkan minat belajar siswa. Proity menyatakan strategi Joyful Learning dapat digunakan pada semua mata pelajaran. Oleh sebab itu strategi tersebut pun berpengaruh dengan baik pada mata pelajaran IPS untuk meningkatkan minat belajar siswa.

Temuan di lapangan mulai dari hasil angket minat belajar IPS, observasi aktivitas siswa, kinerja guru, dan wawancara membuktikan bahwa strategi Joyful Learningberbantuan media Fun Social Puzzledapat meningkatakan minat belajar IPS siswa kelasIV SD N Mangkuyudan tahun ajaran 2017/2018. Strategi Joyful Learningmampu meningkatkan minat belajar IPS siswa dikarenakan dalam pelaksanannya sesuai dengan langkah-langkah strategi tersebut. Langkahnya menurut Septiawan (2012) ialah 1) tahap perisapan, 2) tahap penyampaian, 3) tahap pelatihan dan 4) tahap penutup. Selanjutnya media yang digunakan berupa puzzle juga mempengaruhi peningkatan minat belajar IPS siswa. Sebab media puzzle mempunyai beberapa kelabihan yang benar-benar dapat meningkatkan minat balajar IPS siswa. Kelebihan tersebut menurut Susanti (2012) yaitu: 1) melatih daya ingat dan psikomotorik, 2) meningkatkan gairah belajar siswa.

Berdasarkan hasil penelitian akan penggunaan strategi Joyful Learningberbantuan media Fun Social Puzzledalam proses pembelajaran IPS di SD N Mangkuyudan. Hal tersebut sudah sesuai dengan yang dituturkan oleh Darmansyah (2014:24) bahwa strategi Joyful Learningmerupakan suatu strategi pengorganisasian pembelajaran dengan fokusnya ialah daya tarik siswa akan pembelajaran, melalui bahan ajar yang disampaikan, media pembelajaran yang digunakan, serta pengalokasian waktu/ jam pelajaran. Selain itu,dalam strategi Joyful Learningini pembelajaran juga didesain sedemikian rupa sehingga memberikan suasana penuh keceriaan, menyenangkan dan yang paling utama pembelajaran tidak membosankan (Djamarah, 2008).

Tak lupa media yang digunakan juga sudah sesuai dengan pendapat Faishal (2014) bahwa puzzle merupakan media yang digunakan untuk menyalurkan pesan dari pengirim (guru) dan penerima (siswa) melalui permainan kontruksi, merangkai potongan-potongan gambar, yang tentunya dapat merangsang pikiran, perasaan, perhatian serta minat siswa dalam proses pembelajaran. Dengan pengaturan tersebut sehingga siswa memiliki daya tarik dalam dirinya yaitu minat belajar untuk mau belajar. Jika sudah mempunyai modal dasar ketertarikan belajar, siswa akan mudah menerima pembelajaran. 


\section{SIMPULAN}

Berdsarkan hasil analisis data dan pembahasan maka disimpulkan bahwa strategi Joyful Learningberbantuan media Fun Soial Puzzledapat meningkatkan minat belajar IPS siswa kelas IV SD N Mangkuyudan tahun ajaran 2017/2018.

Berkaitan dengan hasil penelitian, peneliti mengajukan saran. Bagi guru, agar lebih terbuka dengan strategi dan media baru seperti strategi Joyful Learningditambah media Fun Social Puzzle. Bagi siswa lebih mempersiapkan diri untuk belajar agar dapat fokus, konsentrasi dalam pembelajajaran, seperti saat menggunakan strategi Joyful Learningberbantuan media Fun Scoial Puzzle. Bagi sekolah hendaknya memberikan kesempatan dan motivasi kepada guru untuk menggunkan strategi dan media yang inovatif dan efektif serta lebih memperhatikan minat siswa dalam belajar. Bagi peneliti lain, lebih mempersiapakan dengan matang sehingga hasilnya dapat memuaskan, serta untuk menambah kajian-kajian agar lengkap.

\section{DAFTAR PUSTAKA}

Darmansyah. (2014). Startegi pembelajaran menyenangkan dengan Humor. Jakarta: Bumi Aksara.

Djamarah, S B. (2008). Psikologi Belajar. Jakarta: Rineka Cipta.

Faishal, Y BA. (2014). Meningkatkan Interaksi Sosial Melalui Layanan Penguasaan Konten Dengan media PuzzlePadaSiswaKelas X SMA Negeri 1 Semarang Tahun Pelajaran 2014/2015. Vol 1 No1. ISSSN 2406-8691.

Permatasari, Intan dkk (2014). Efektifitaspenggunaan Model PembelajaranJoyful LearningdenganMetodePemberianTugasterhadapPrestasiBelajarSiswa pada Materi Pokok Koloid Siswa Kelas XII IPA SMA Negeri 1 SimotahunPelajaran 2012/2013. ISSN, 2337-9995

Proity, S. (2013). Effect of Joyful Teaching on Grade IV Students Academc Performance in Science. ISSSN 2319-7064. Bangladesh: Asian Universty of Bangladesh.

Septiawan, H. (2012). Penerapan Metode Pembelajaran Berbasis Joyful Learning untuk Meningkatkan Motivasi dan hasil Belajar Siswa Mata Pelajaran Matematika Kelas IV SDN Salatiga 01 Kota Salatiga. Salatiga: Universitas Kristen Satya Wacana.Dunduhpadatanggal 20 januari 2018.

Susanti. (2012). Media Pembelajaran Puzzle. Diambil darihttp://susanti25.blogspot.co.id/2012/11/media-pembelajaran-puzzle.html. Diakses pada tanggal 20 Januari 2018.

Syah, M. (2012). Psikologi Belajar. Jakarta: Rajawali Press.

Wei, Chun, Wang. (2011). A Joyful Classroom Learning System With Robot Learning Companion For Children to Learn Mathematics Multiplication. Vol 2 Issue 2. Turkish:Far East University Taiwan.

Widyanarti, S. (2014). Penggunaan Media puzzle Dalam Model Pembelajaran Langasung Untuk Meningkatkan Hasil Belajar Siswa Pada Mata Pelajaran IPS Kelas $V$ A SDN Rangkah 1 Tambaksari Surabaya. Surabaya: UniversitasNegeri Surabaya. 